\title{
PASOS HUMANOS Y PASOS DE DIOS EN EL PROCESO MIGRATORIO
}

\author{
Hna. Josie Desamours, mscs*
}

Plasmar la propia vivencia sobre el papel, resulta bastante complejo porque ya son más de 15 años, si no me equivoco, que deje mi tierra - Haiti - e que vivo esta experiencia de "ser migrante con las personas migrantes" en los países de: República Dominicana, Brasil, Italia, India y Costa Rica. Esto implica mover sentimientos, emociones, experiencias, revivir momentos de alegría, de gozos, también revivir momentos de dolor, de frustración, que son al final los altibajos de la vida. Pero es a la vez gratificante, porque es un modo de mirar hacia atrás y descubrir los pasos de Dios en la historia personal, en la historia de la humanidad, contemplar los momentos de luces y sombras en este proceso de peregrinar.

Entonces, hablar de la experiencia personal es volver la mirada hacia atrás, contemplarse, mirarse, mirar el mundo, a través de los ojos del corazón, los ojos de la fe para descubrir en ese peregrinar, las huellas de las personas que por su misma presencia han dejado infinitas huellas en nuestra mente, en nuestro corazón.

Todo este movimiento, todos estos procesos han dado una razón de ser a mi vida como persona, religiosa consagrada y misionera de la Congregación Misionera de San Carlos Borromeo-Scalabrinianas, pero sobretodo como migrante, porque he aprendido a descubrir a Dios también en esta experiencia de ser migrante, como Dios ha tejido el hilo de mi vida y como El sigue tejiéndola en el tiempo y el espacio.

\footnotetext{
* Vicaria Episcopal de la Pastoral Social Arquidiocesis de San José, Costa Rica Coordinadora de la Pastoral Migratoria. San José/Costa Rica.
} 
La migración me ha enseñado a descubrir que la única seguridad permanente es Dios. Es el amor manifestado en las personas que son nuestras compañeras de viaje. Pero esa seguridad no es experimentada de una vez por toda, sino es un proceso que se va adquiriendo justamente en esta dinámica de la migración y la misma vivencia diaria va fortaleciendo esta convicción.

En este sentido, podemos recordar la vivencia de esta seguridad en nuestra Cofundadora Madre Assunta Marchetti y Padre José Marchetti que tuvieron la valentía de dejar Italia, emprendiendo el camino hacia Brasil y transformándose ellos mismos en migrante con los migrantes. Sus vidas se derritieron como vela para dar luz a la humanidad: a los hijos y las hijas de los migrantes italianos. La única seguridad que los dos tenían era la fe en la Providencia de Dios. Y como la única seguridad era Dios entonces, se volvieron los dos: hombre y mujer de Dios para los forasteros más pequeños, débiles, hambrientos, huérfanos.

Desde luego, como cada persona es un ser único, por lo tanto, las percepciones, las vivencias las experiencias son diferentes y la forma de enfrentar los desafíos que se presentan en el proceso migratorio es única. Viví como migrante por querer realizar un sueño, el sueño de servir a Dios en los más débiles, los más sufridos (cf. Mt 25,35).

Estando en mi país, creía en la existencia de Dios, porque esta experiencia me fue transmitida por la familia, la Iglesia, el entorno donde nací, crecí. Mis seguridades eran: mi país, mi familia, mi madre en quien me aferraba tanto, mis estudios, mis amigos, las costumbres, las tradiciones. Pero en la migración se desvanecen todas estas seguridades.

En este caminar, como es normal para muchos, viví la experiencia de sentirme como un pez fuera del agua, insegura, temerosa, invisible, vulnerable y mi única seguridad era aprender a creer en la Providencia de Dios. Y por medio de esa fe, pude presenciar tantos milagros, tantas maravillas en este camino de peregrinación.

Aprendí a descubrirme a mí misma, mi identidad, mi ser de mujer, mis potencialidades, mis debilidades, mis anhelos. Aprendí a sentirme verdaderamente amada por Dios, no de una forma abstracta sino aprendí a descubrir este amor, esta protección en cada persona que me ha acompañado en este caminar, personas que me han ayudado a vencer los grandes desafíos de la vida, a cruzar las calles de las inseguridades, a cruzar la calle del temor. 
Descubrí que la familia sanguínea es la primera, pero no es la última y absoluta, porque nuevos lazos familiares se forman, nuevos vínculos de hermandad se entretejen, nuevos lazos de amistad se cruzan y formamos una familia sin ser de la misma nacionalidad, sin tener ningún vínculo sanguíneo. Y esa experiencia de lazos de hermandad nos hace disfrutar en potencia de la vida de Dios, esa vivencia nos vislumbra el verdadero sueño de Dios: Hacer un solo pueblo de un mismo Padre celestial.

El primer país que me acogió como migrante fue República Dominicana, tal vez la palabra acoger es un poco inapropiada porque en República Dominicana las personas de nacionalidad haitiana no son bienvenidas por diferentes razones histórica, ideológica y cultural y otras que tal vez desconozco. Por lo tanto, no fue fácil la adaptación, y mucho menos la integración. El mayor obstáculo encontrado no fue el idioma español, sino por ser lo que soy: migrante de origen haitiano. ¿Cómo puede sentir una persona migrante viviendo en República Dominicana ante esta mentalidad?

Entonces, justamente en esta realidad me tocó hacer mi primera experiencia de ser migrante con los migrantes. Desarrollé mi misión como Scalabriniana, acompañando a los migrantes haitianos viviendo en los bateyes del este de Republica Dominicana. Allí fui testigo de las grandes oportunidades que tienen los migrantes para trabajar, un techo donde reclinar la cabeza, pero al mismo tiempo presencié los frutos amargos del individualismo, de la avaricia, del egoísmo, el fruto amargo del sistema capitalista y como los prejuicios hacia los migrantes haitianos ciegan los ojos, endurecen el corazón, cierran las manos, paralizan los pies e impiden ir al encuentro del otro, valorar el otro por lo que es, considerar el otro, un otro igual que yo.

En estos lugares marginados llamados "Bateyes" se puede contemplar los rostros de niños y niñas excluidos en la educación por ser apátridas, rostros de adolescentes y jóvenes que pierdan la ilusión y esperanza en una mañana mejor, la miseria de tantos hombres y mujeres que han donado su sangre, su juventud en la dura labor de la industria azucarera, pero ya al final son abandonados y se vuelven invisibles a los ojos de la sociedad y condenados a morir de hambre, de sed, morir por falta de amor en una habitación teniendo como única compañía la soledad en espera de la muerte. 
Nuestra presencia como Hermanas Scalabrinianas fue de ser esa pequeña gota de bálsamo para sanar aquellos corazones afligidos, ayudarlos a descubrir los pasos de Dios aún en esta realidad. En este proceso migratorio, aprendí a seguir creyendo en Dios aunque a veces esa fe se vaciló y quise, en algún momento, transformarme en discípulo de Emaús, volver a mi país, a la tierra donde nací y cerrar los ojos para no ver esa realidad.

Desde allí en esta dura y cruda realidad de los bateyes, mi vocación misionera se afianzó, se fortaleció, yo seguía diciendo: "si Señor, yo creo, pero aumente mi pobre fe". Allí también aprendí a afianzar mi identidad, descubrir que Dios me llama a servirlo en estas realidades. Esta convicción me dio ala para seguir, en el caso contrario mi presencia no hubiera tenido ninguna razón de ser, por esto hoy, por hoy, agradezco a Dios, porque soy lo que soy hoy también gracias a estas experiencias.

Otra experiencia que me ha marcado profundamente la vida es el tiempo que he vivido en Italia. Fue una experiencia maravillosa, desafiante desde el aprender un nuevo idioma, integrarme en el mundo de la pluriculturidad existente en Roma con la presencia de los diferentes rostros de migrantes: africanos, asiáticos, indianos, albaneses, rumanos, brasileños, haitianos, españoles, franceses... Cada uno con su belleza, sus peculiaridades, cada migrante desde el silencio del corazón lleva consigo un sueño, un sueño indestructible.

He convivido en una comunidad con hermanas de diferentes países, como por ejemplo: Albania, Italia, Brasil, Republica Dominicana, Paraguay. Sobre todo tuve la oportunidad de estudiar en una universidad con personas como: laicos, laicas consagradas religiosas, sacerdotes procedentes de los cinco continentes, todos y todas con el propósito de consolidar la fe en Dios, de conocer más de cerca la vida de Dios, su plan de salvación para todas las naciones (cf. Mt 28,19).

Y qué emoción me estremecía cuando caminaba por estos caminos donde pasaron tantos santos, mártires del amor de Dios, mártires de la verdad, de tantos hombres y mujeres que dieron sus vidas en defender la justicia, el respecto y defensa de los derechos humanos. Que emoción experimentaba cuando caminaba por los lugares donde nacieron nuestro fundador Beato Juan Bautista Scalabrini y co-fundadores: Madre Assunta y P. José Marchetti, San Carlos Borromeo. Estas experiencias infinitas han 
contribuido en el fortalecimiento de mi identidad como católica y como misionera Scalabriniana.

Otra experiencia juzgo importante poner en evidencia es: mi presencia como misionera en el norte de India, la ciudad de Kerala. Prácticamente en India, fue bastante compleja la experiencia en relación sobre todo con el idioma, porque en India existen un infinito tipo de idiomas, como por ejemplo: Asamés, Bengalí, Bodo, Cachemiro, Dogri, Guyaratí, Hindi, Konkani, Maithili, Malayalam, Manipurí, Maratí, Nepalí, Oriya, Punjabí, Sánscrito, Santalí, Sindhi, Tamil, Telugu, Urdu, y no sabía ningún de ellos, excepto poder saludar en Malayalam.

En mi experiencia en las comunidades donde iba desarrollar mi misión necesitaba siempre un intérprete porque no bastaba conocer solo el inglés y además no todas las personas hablan o entienden inglés. Y cada comunidad donde iba, la gente hablaba un idioma diferente. En sí una sola persona puede dominar tres o más idiomas o dialectos según la zona donde están ubicados.

Entonces, como realizar la misión en un país sin conocer ninguno de estos idiomas, sin conocer a nadie por los lugares donde uno iba. Pues bien me hice especialista en el idioma del gesto. Yo iba por dondequiera usando como herramientas de comunicación: expresiones faciales, labiales, los movimientos de las manos, etc.

Esta experiencia me ha enseñado a comprender que no existe ninguna barrera inquebrantable, insuperable entre los seres humanos. Somos nosotros que la construimos, por ejemplo las barreras del odio, de la indiferencia, las ideologías, las costumbres, las condiciones sociales, el color de la piel, o por ser indio, negro, blanco, mulato como queramos Ilamarlo.

Estas barreras son construidas por nosotros mismos y estas mismas nos llevan a destruir a nosotros mismos y también a los otros.

Ahora desde hace tres años estoy realizando mi misión como misionera en Costa Rica. Actualmente estoy coordinando la Pastoral Migratoria en la Arquidiócesis de San José y al mismo tiempo estoy cursando la licenciatura en Piscología. Aquí vivo mi ser migrante con los migrantes nicaragüenses, colombianos, panameños por citar algunos. Y aquí también, la historia se repite con los fenómenos de estigmatización y exclusión social de la población sobre todo nicaragüense de tipo 
etnocentrista y nacionalista, cuya reproducción perpetúa las prácticas de discriminación y segregación de esta comunidad en muchos espacios.

Todas esas experiencias me hacen entender que necesitamos testimoniar con nuestras vidas que el amor de Dios no es una utopía en un mundo donde prevalecen el individualismo, el etnocentrismo, el egocentrismo, la soberbia, la cultura del yo, la indiferencia. Por lo tanto, estamos llamados a vivir en esta realidad, construir solidaridad, acogida, vivir la fraternidad en la pluralidad, propiciando el dialogo y el compartir.

Que podamos aprender a caminar humildemente con nuestro Dios (cf. Mq 6, 8) en nuestro proceso de peregrinación y transformándonos en compañeras y compañeros de viaje, donde las diferencias sean armonizadas por el Espíritu y la caridad se haga auténtica en la aceptación del otro no por lo que representa o posee sino por lo que es: de la misma familia humana, hijo amado de Dios. A pesar de todo, todos somos extranjeros y peregrinos en esta tierra (cf. $\mathrm{Hb} 11,13$ ), todos en camino hacia la verdadera patria donde viviremos el nacimiento de un pueblo nuevo, la Iglesia de Jesucristo (Gal 3,28). 